\title{
Clinical significance of metabolic tumor volume by PET/CT in stages II and III of diffuse large B cell lymphoma without extranodal site involvement
}

\author{
Moo-Kon Song • Joo-Seop Chung • Ho-Jin Shin • Sang-Min Lee • Su-Ee Lee • \\ Ho-Sup Lee • Gyeong-Won Lee • Seong-Jang Kim • Seok-Mo Lee • Dong-Seop Chung
}

Received: 17 May 2011 / Accepted: 17 October 2011 /Published online: 11 November 2011

(C) The Author(s) 2011. This article is published with open access at Springerlink.com

\begin{abstract}
The objective of this study was to investigate whether metabolic tumor volume (MTV) by positron emission tomography (PET) can be a potential prognostic tool when compared with Ann Arbor stage, in stages II and III nodal diffuse large B cell lymphoma (DLBCL). We evaluated 169 patients with nodal stages II and III DLBCL who underwent measurements with PET prior to rituximab combined with cyclophosphamide, adriamycin, vincristine, and prednisone (R-CHOP). Cutoff point of MTV was measured using the receiver operating characteristic (ROC) curve. During a median period of 36 months, stage II was $59.2 \%$ and III was $40.8 \%$. Using the ROC curve, the MTV of $220 \mathrm{~cm}^{3}$ was the cutoff value. The low MTV group $\left(<220 \mathrm{~cm}^{3}\right)$ had longer progression-free survival (PFS) and overall survival (OS), compared with the high MTV group $\left(\geq 220 \mathrm{~cm}^{3}\right)(p<0.001, p<0.001)$. Stage II patients had longer survival than those in stage III (PFS, $p=0.011$; OS, $p=$ 0.001). The high MTV group had lower PFS and OS patterns, regardless of stage, compared with the low MTV
\end{abstract}

M.-K. Song $\cdot$ J.-S. Chung $(\bowtie) \cdot$ H.-J. Shin

Department of Hematology-Oncology, Busan Cancer Center, Pusan National University Hospital Medical Research Institute, 1-10 Ami-dong, Seo-gu,

Busan 602-739, Republic of Korea

e-mail: Hemon@pusan.ac.kr

\section{S.-M. Lee}

Department of Hematology-Oncology, Busan Paik Hospital,

Busan, South Korea

S.-E. Lee

Department of Hematology, Dong-A University Medical Center,

Busan, South Korea

H.-S. Lee

Department of hematology, Kosin University Gospel Hospital, Busan, South Korea group $(p<0.001, p<0.001)$. Multivariate analysis revealed an association of the high MTV group with lower PFS and OS (PFS, hazard ratio $(\mathrm{HR})=5.300, p<0.001 ; \mathrm{OS}, \mathrm{HR}=$ 7.009, $p<0.001$ ), but not stage III (PFS, $p=0.187$; OS, $p=$ 0.054). Assessment of MTV by PET had more potential predictive power than Ann Arbor stage in the patients that received R-CHOP.

Keywords Diffuse large B cell lymphoma · Positron emission tomography $\cdot$ Rituximab

\section{Introduction}

Introduction of rituximab combined with cyclophosphamide, adriamycin, vincristine, and prednisone (R-CHOP) has resulted in improved survival outcomes in patients with diffuse large B cell lymphoma (DLBCL) [1-8]. DLBCL is a heterogenous group of $\mathrm{B}$ cell non-Hodgkin lymphoma

G.-W. Lee

Department of hematology, Gyeongsang National University Hospital,

Jinju, South Korea

S.-J. Kim

Department of Nuclear Medicine, Pusan National University Hospital,

Busan, South Korea

S.-M. Lee

Department of Nuclear Medicine, Busan Paik Hospital, Busan, South Korea

D.-S. Chung

Industry-University Cooperation Foundation, Kyung Sung

University,

Busan, South Korea 
(NHL), rather than a single clinicopathologic entity [9]. Multiple histologic subtypes were recognized and several molecular and genetic abnormalities were variably present. In recent years, most studies have focused on identifying molecular markers in order to define new prognostic factors. However, no relevant prognostic molecular markers have been validated, and an agreement on prognostic models has not yet been reached [10].

Aggressive NHL, including DLBCL, has been staged according to the Ann Arbor staging system, which was originally designed for Hodgkin lymphoma (HL). The International Prognostic Index (IPI) is the primary clinical tool used to predict the outcome for patients with aggressive NHL based on the number of negative prognostic factors at the time of diagnosis, including Ann Arbor stage III/IV and other factors (age $\geq 60$ years, elevated lactate dehydrogenase level, Eastern Cooperative Oncology Group performance status $\geq 2$, more than one extranodal site) [11]. However, due to the higher heterogeneity and hematogenous spread pattern of dissemination in NHL relative to contiguous lymphatic spread with HL, Ann Arbor staging system has limited value in the context of assessing accurate tumor burden in NHL. For instance, despite the presence of a high tumor burden in stage II disease, the IPI score can be "zero point," whereas the score can be "one point" in stage III disease even if the tumor burden is low.
New imaging techniques such as $18 \mathrm{~F}$-fluorodeoxyglucose $\left({ }^{18} \mathrm{~F}-\mathrm{FDG}\right)$ positron emission tomography (PET) have been used as prognostic tools in NHL $[12,13]$. As indicated by several positive sets of data, imaging techniques have become an important tool in clinical decisions on therapeutic strategies for treating aggressive NHL, including DLBCL [14-16]. The objective of the present study was to investigate whether metabolic tumor volume (MTV) by PET can be used as a potential prognostic tool, compared with the Ann Arbor stage, in patients with stages II and III nodal DLBCL.

\section{Materials and methods}

One hundred sixty-nine patients with de novo nodal DLBCL between July 2004 and November 2008 in five medical centers (Pusan National University Hospital, Dong-A University Medical Center, Kosin University Gospel Hospital, Busan Paik Hospital, and Gyeongsang National University Hospital) who underwent PET-CT at diagnosis were enrolled in the present study. All patients received six to eight cycles of R-CHOP therapy according to Coiffier et al [1]. The median follow-up duration was 36 months, and the male-to-female ratio was $1.56: 1$ (Table 1).

Table 1 The baseline characteristics and comparison between stages II and III nodal DLBCL patients

\begin{tabular}{|c|c|c|c|c|}
\hline & Total $(n=169)(\%)$ & Stage II $(n=100)(\%)$ & Stage III $(n=69)(\%)$ & $p$ value \\
\hline Age, median, years (range) & $61.0(21-79)$ & $62(22-79)$ & $59(21-76)$ & 0.327 \\
\hline Sex, male/female & $103 / 66$ & $63 / 37$ & $40 / 29$ & 0.511 \\
\hline \multicolumn{5}{|l|}{ Disease status } \\
\hline Age $\geq 60$ years & $98(60.0)$ & $63(63.0)$ & $35(50.7)$ & 0.113 \\
\hline Elevated LDH & $77(45.6)$ & $43(43.0)$ & $34(49.3)$ & 0.422 \\
\hline ECOG at least 2 & $42(24.9)$ & $21(21.0)$ & $21(30.4)$ & 0.164 \\
\hline B symptoms & $71(42.0)$ & $37(37.0)$ & $34(49.3)$ & 0.113 \\
\hline Bulky LN ( $\geq 5 \mathrm{~cm})$ & $7(4.1)$ & $3(3.0)$ & $4(5.8)$ & 0.911 \\
\hline MTV, median, $\mathrm{cm}^{3}$ (range) & $198.1(4.5-1,990.7)$ & $122.1(4.5-1,251.1)$ & $434.3(10.1-1,990.7)$ & $<0.001$ \\
\hline IPI score, $n(\%)$ & & & & 0.070 \\
\hline $0-2$ & $125(73.9)$ & $78(78.0)$ & $47(68.1)$ & \\
\hline $3-4$ & $44(26.1)$ & $22(22.0)$ & $22(31.8)$ & \\
\hline \multicolumn{5}{|l|}{ Response by revised IWC } \\
\hline $\mathrm{CR}$ & $142(84.0)$ & $87(87.0)$ & $61(88.4)$ & 0.786 \\
\hline PR & $21(12.4)$ & $13(13.0)$ & $5(7.2)$ & 0.236 \\
\hline SD & $6(3.6)$ & $0(0.0)$ & $3(4.3)$ & 0.036 \\
\hline \multicolumn{5}{|l|}{ Survival (\%) } \\
\hline 3-year PFS & 73.4 & 80.0 & 63.8 & 0.011 \\
\hline 3 -year OS & 76.3 & 85.0 & 64.2 & 0.001 \\
\hline
\end{tabular}

$L D H$ lactate dehydrogenase, $E C O G$ Eastern Cooperative Oncology Group, $M T V$ metabolic tumor volume, IPI international prognostic index, $P F S$ progression-free survival, $O S$ overall survival 
Inclusion and exclusion criteria

Patients were included if they had primary nodal localization as a de novo DLBCL histotype, and the stage was II or III according to Ann Arbor staging and had been available for clinical follow-up. Patients were excluded if they presented any extranodal involved site, DLBCL secondary to low-grade NHL, or other treatment, including radiotherapy after RCHOP therapy or autologous stem cell transplantation and if there was a discrepancy in the LNs between PET and conventional computed tomography (CT). In addition, patients were excluded if they had uncontrolled diabetes mellitus, evidence of infection at the time of diagnosis, especially active tuberculosis, or antibodies against human immunodeficiency virus.

\section{Measurement of MTV by PET/CT}

Dual-modality PET/CT tomography was performed on a biograph (Siemens Medical Solution, Hoffman Estates, IL, USA), based on a dual-slice helical CT and a full-ring PET tomography. FDG-PET images were evaluated for regions of focally increased tracer uptake. In the target lesions of FDG tracer uptake, $\mathrm{SUV}$ of $\geq 2.5$ as contouring border was considered to represent lymphoma, as suggested by Freudenberg et al. [17]. The CT images were used for PET attenuation correction. Imaging reconstruction of corrected emission data was performed after Fourier transform with AWOSEM software (two iterations, eight subsets, $5 \mathrm{~mm}$ Gaussian filter). The CT criterion for pathologic $\mathrm{LN}$ was that the $\mathrm{LN}$ exceeded $1.0 \mathrm{~cm}$ in all regions, except the groin. PET image also evaluated the area of focal tracer uptake; thus, the SUV of $\geq 2.5$ was considered as pathologic LN, and the MTV was measured after $\mathrm{CT}$ attenuation correction. CT images were acquired with $130 \mathrm{mAs}, 130 \mathrm{kV}$, and slice width (or $5 \mathrm{~min}$ and table feed) of $8 \mathrm{~mm}$ per rotation. Intravenous or oral contrast agents were used in all patients, and a standardized breathing protocol was applied. PET images were interpreted by nuclear physicians at each institution. Data were then reviewed by two nuclear medicine experts at Pusan National University Hospital.

Pretreatment and response evaluation

Pretreatment staging and response evaluation after six or eight cycles of R-CHOP therapy were based on clinical examination, CT scan of the neck, chest, abdomen, and pelvis, bone marrow biopsy, and PET/CT. Response was assessed according to revised International Workshop Criteria [14]. Criteria were as follows: complete response (CR) is defined as (a) no signs or symptoms of disease, (b) negative PET and regression to normal size on $\mathrm{CT}$, and (c) normal bone marrow. Partial response (PR) is defined as $50 \%$ decrease in tumor size but with a positive PET at the prior disease site. Stable disease
(SD) is defined as (a) positive PET at the prior sites of disease and no new sites on CT or PET and (b) PET negative and no change in size of previous lesions on CT. Progressive disease is defined as (a) appearance of a new lesion $>1.5 \mathrm{~cm}$ in any axis, $\geq 50 \%$ increase in the sum of the product of the diameters of more than one node, or $\geq 50 \%$ increase in the longest diameter of a previously identified node $>1 \mathrm{~cm}$ in short axis and (b) lesions PET positive if FDG-avid lymphoma or PET positive prior to therapy.

\section{Statistical analyses}

The Mann-Whitney $U$ test was used for assessment of differences in the frequency-independent prognostic factors of stages II and III groups. Progression-free survival (PFS) was calculated from the date of diagnosis to documented disease progression; observations were censored on the date the patient was last known to be alive or, for patients dying as a result of causes unrelated to lymphoma or treatment, the date of death. Overall survival (OS) was calculated from the date of diagnosis until death as a result of any cause or the date last known to be alive. PFS and OS were estimated by the Kaplan-Meier method, and the difference was compared using a log-rank test. Receiver operating characteristic (ROC) curve was performed for estimation of the accuracy in prediction of ideal cutoff value of MTV. Estimation of sensitivity and specificity was based on the cutoff value of MTV. SPSS software for Macintosh (SPSS 15.0; Chicago, IL, USA) was used for statistical data processing. A probability value $<0.05$ was considered statistically significant.

\section{Results}

\section{Patient characteristics}

One hundred sixty-nine patients with stage II/III nodal DLBCL were treated with R-CHOP from 2004 to 2008, and the baseline characteristics were summarized in Table 1. Differences of several independent prognostic factors between stages II and III groups were not observed. However, MTVs in the stage III group were larger when compared with the stage II group $(p<0.001)$. CR and PR of the treatment response were comparable between the two groups ( $p=0.786, p=0.236$, respectively), whereas $\mathrm{SD}$ was higher in the stage III group when compared with the stage II group ( $p=0.036$, Table 1$)$.

Measurement of cutoff value of MTV in patients at diagnosis

ROC curve analysis was employed to calculate the accuracy of the ideal cutoff value, which was used to distinguish the low 


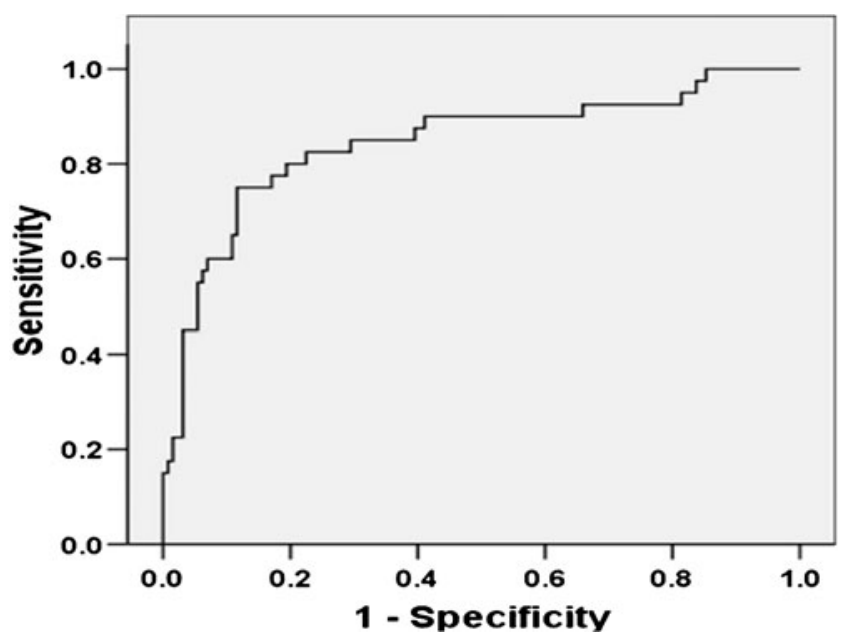

Fig. 1 Receiver operating characteristic curve analysis in survival prediction according to MTV in 160 stages II and III nodal DLBCL patients (continuous variable). Area under the curve was $0.857(p<0.001$, $95 \%$ CI $0.782-0.932$ ), and $220 \mathrm{~cm}^{3}$ was determined as the cutoff value of MTV for comparison. Sensitivity and specificity of the dichotomized MTV ( $\geq 220$ versus $<220$ ) were $91.7 \%$ and $65.3 \%$, respectively

MTV group from the high MTV group. The estimated area under the ROC curve was $0.857(p<0.001 ; 95 \%$ conference
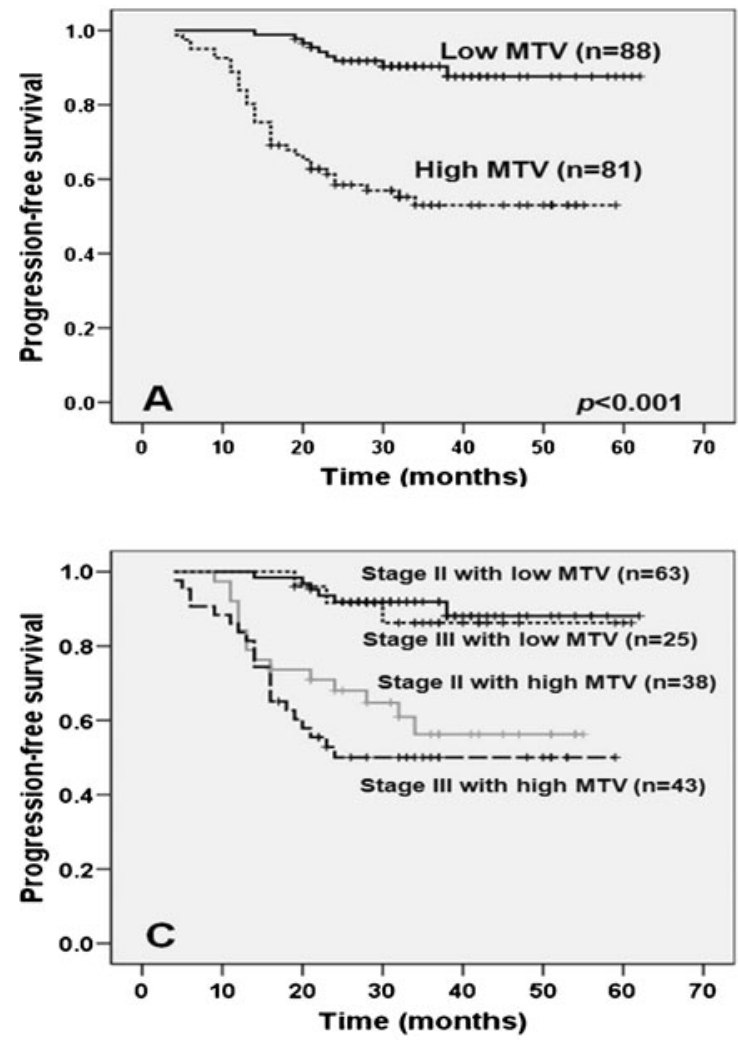

Fig. 2 Comparisons of survival according to the cutoff value of MTV and stage combined with the cutoff value of MTV. a PFS and $\mathbf{b}$ OS according to the cutoff value of MTV were higher in the low MTV group compared with the high MTV group (PFS $<0.001$; OS, $p<0.001$, respectively). c PFS and d OS of stages II and III with the low MTV groups were higher compared with other groups, whereas survival interval, 0.782-0.932), which suggests that the value was important to prediction of survival. Various cutoff values of MTV were used to obtain a reasonable balance of sensitivity and specificity; $220 \mathrm{~cm}^{3}$ of various values acquired a sensitivity of $91.7 \%$ and specificity of $65.3 \%$ (Fig. 1).

Clinical outcome according to stage or MTV

Three-year PFS and OS were significantly higher in the stage II group than in the stage III group (PFS, $80.0 \%$ in stage II versus $63.8 \%$ in stage III, $p=0.011$; OS, $85.0 \%$ in the stage II group versus $64.2 \%$ in stage III, $p=0.001$, Table 1). Clinical outcome according to the low MTV group versus the high MTV group was also analyzed, and the results were shown in Fig. 2a, b. PFS and OS were significantly higher in the low MTV group than in the high MTV group (PFS 89.8\% versus $55.6 \%, p<0.001$; OS $93.2 \%$ versus $58.0 \%, p<0.001$ ).

Clinical outcome according to stage combined with MTV

Further analysis was performed to determine whether tumor burden was of clinical importance between stages II and III
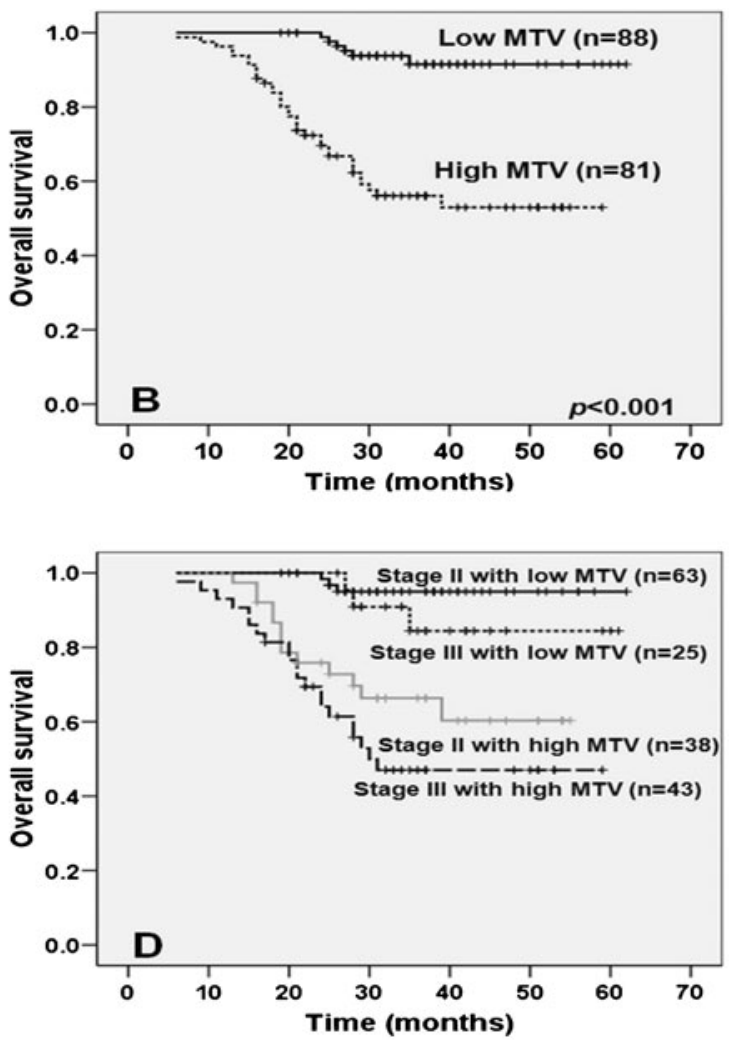

between the two low MTV groups (PFS 90.5\% in stage II versus $88.0 \%$ in stage III, $p=0.703$; OS $95.2 \%$ in stage II versus $88.0 \%$ in stage III, $p=0.268$ ) or high MTV groups (PFS $60.5 \%$ in stage II versus $51.2 \%$ in stage III, $p=0.347$; OS $65.8 \%$ in stage II versus $51.2 \%$ in stage III, $p=0.175$ ) were not different 
Table 2 Univariate analysis for prognostic factors in patients

\begin{tabular}{|c|c|c|c|c|}
\hline \multirow[t]{2}{*}{ Prognostic factors } & \multicolumn{2}{|l|}{ Progression-free survival } & \multicolumn{2}{|l|}{ Overall survival } \\
\hline & HR $(95 \% \mathrm{CI})$ & $p$ value & HR $(95 \% \mathrm{CI})$ & $p$ value \\
\hline Stage III & $2.094(1.162-3.773)$ & 0.014 & $2.758(1.454-5.234)$ & 0.002 \\
\hline High MTV & $5.797(2.787-12.055)$ & $<0.001$ & $8.097(3.395-19.309)$ & $<0.001$ \\
\hline
\end{tabular}

nodal DLBCL patients. Outcomes were compared among the four subgroups based on tumor burden and stage II or III (stage II group with low MTV, stage II group with high MTV, stage III group with low MTV, and stage III group with high MTV). The high MTV group, regardless of stage, had lower PFS and OS patterns, compared with the low MTV group (PFS and OS in stage II with low MTV, 90.5\% and 95.2\%; in stage III with low MTV, $88.0 \%$ and $88.0 \%$ versus in stage II with high MTV, $60.5 \%$ and $65.8 \%$; in stage III with high MTV, 51.2\% and $51.2 \% ; p<0.001, p<0.001)$, whereas the prognostic impact of stage in the same MTV group was absent (in the low MTV group, difference of PFS and OS according to stage, $p=0.703$, $p=0.268$; in the high MTV, $p=0.347, p=0.175$, Fig. $2 \mathrm{c}, \mathrm{d}$ ).

Univariate and multivariate analysis

In the univariate analysis, stage III was still a poor prognostic factor for PFS and OS (PFS, hazard ratio $(\mathrm{HR})=2.094,95 \%$ confidence interval $(\mathrm{CI})=1.162-3.773, p=0.014$; OS, HR= $2.758,95 \% \mathrm{CI}=1.454-5.234, p=0.002$ ). In addition, high MTV was also shown to be a predictive parameter for poor survival (PFS, $\mathrm{HR}=5.799,95 \% \mathrm{CI}=2.787-12.055, p<0.001$; OS, $\mathrm{HR}=8.097,95 \% \mathrm{CI}=3.395-19.309, p<0.001$, Table 2). To further investigate the prognostic value of high MTV, multivariate analysis using a Cox proportional hazard model was performed on the high MTV and stage III groups. This analysis showed that high MTV was an independent factor for the prediction of an unfavorable outcome (PFS, $\mathrm{HR}=5.300$, $95 \% \mathrm{CI}=2.517-11.162, p<0.001$; OS, $\mathrm{HR}=7.009,95 \% \mathrm{CI}=$ 2.902-16.927, $p<0.001$ ), whereas stage III had no significant value $(\mathrm{PFS}, \mathrm{HR}=1.496,95 \% \mathrm{CI}=0.822-2.724, p=0.187$; $\mathrm{OS}$, $\mathrm{HR}=1.894,95 \% \mathrm{CI}=0.988-3.628, p=0.0 .054$, Table 3 ).

\section{Discussion}

Since its publication in 1971, Ann Arbor staging has been used as the staging system for both HL and NHL lymphomas
[15]. However, the number of involved nodal sites was not considered in this optional staging system. For these reasons, the Ann Arbor scheme was revised, and modifications in the staging procedures were recommended within the framework of the Ann Arbor Classification by a committee meeting in the Cotswolds under the auspices of the Cancer Research Campaign and Imperial Cancer Research Fund [16]. However, accurate tumor burden was also not considered in the staging system. Interestingly, one previous study demonstrated that tumor burdens could be discriminated (i.e., low tumor burden vs. high burden) based on the number of extensive nodal areas and extranodal sites [18]. The author of this study suggested that tumor burden measured by their method was an excellent prognostic factor in CHOP era. However, this method only involved a simple arithmetic system, and no imaging techniques were utilized. Because accurate tumor surveillance is a fundamental precondition for assessment of prognosis and therapeutic options in patients with NHL, a more accurate staging system model should be developed, especially in the era of rituximab.

A recent meta-analysis study, based on data from three large clinical trials, suggested that treatment with rituximab resulted in significant improvement of the treatment outcome within each of the four IPI factors, including Ann Arbor stage [19]. Of particular interest, the study revealed data from the MabThera International Trial, where the advanced stage (III/IV) was no longer an independent factor of OS in multivariate analysis. In this study, data from the MegaCHOEP Trial also demonstrated that the advanced stage showed borderline correlations with PFS and was not associated with OS. In addition, data from the RICOVER-60 trial shown in this study demonstrated that the advanced stage was not an independent factor of PFS and OS. These findings indicate that treatment with rituximab resulted in improved outcome of advanced stage patients and diminished gap of survival between the limited stage and advanced stage according to the Ann Arbor staging system. For these reasons, we do not believe that the advanced stage itself would be a true poor
Table 3 Multivariate analysis for prognostic factors in patients

\begin{tabular}{|c|c|c|c|c|}
\hline \multirow[t]{2}{*}{ Prognostic factors } & \multicolumn{2}{|c|}{ Progression-free survival } & \multicolumn{2}{|l|}{ Overall survival } \\
\hline & HR $(95 \%$ CI $)$ & $p$ value & HR $(95 \%$ CI $)$ & $p$ value \\
\hline Stage III & $1.496(0.822-2.724)$ & 0.187 & $1.894(0.988-3.628)$ & 0.054 \\
\hline High MTV & $5.300(2.517-11.162)$ & $<0.001$ & $7.009(2.902-16.927)$ & $<0.001$ \\
\hline
\end{tabular}


prognostic factor in the era of rituximab. According to the results of meta-analysis in the above clinical trial, the authors demonstrated that four IPI factors were independent factors. However, it did not address several discrepancies, including patient characteristics, using regimens other than CHOP and a different treatment schedule in each clinical trial.

Development of imaging techniques such as ${ }^{18} \mathrm{~F}-\mathrm{FDG}$-PET has resulted in increased diagnostic accuracy and allowed clinicians to distinguish primary malignant lesions from benign areas. Thus, ${ }^{18} \mathrm{~F}$-FDG-PET has been reported to provide superior information on staging of NHL when compared with conventional CT scans. Interestingly, two recent studies showed that tumor burden measured by PET could be used to measure the actual tumor burn of lymphoma [20,21]. One of these studies showed that active tumor burden based on PET might be a prognostic indicator of volumetric response [21]. Volume assessment in these studies was based on percent reduction in $\mathrm{SUV}_{\max }$. However, in the present study, we used a volume measurement process that included a cutoff value of absolute SUV volume measurement, as described by Freudenberg et al. [17].

PET using the tracer ${ }^{18} \mathrm{~F}$-FDG incorporates metabolic tumor function with anatomic localization. Tumor volumes by PET in solid tumors have been associated with clinical outcome in several studies [22, 23]. However, to the best of our knowledge, clinical application of tumor burden by PET as a new staging tool has not yet been reported in DLBCL patients treated with R-CHOP therapy.

The findings reported in the present study suggest that total tumor burden of lymphoma is a more important prognostic parameter than Ann Arbor stage for assessing DLBCL. In the multivariate analysis, a high MTV had a greater clinical significance than stage III in survival. This result demonstrates that the Ann Arbor staging system has limited use in assessing DLBCL due to the heterogenous spread pattern of NHL in contrast to HL. Therefore, overall assessment of tumor burden of lymphoma may be needed before treatment strategies can be developed. In addition, the clinical outcome was not different for the patients in the same MTV state; however, the stage was different. These results suggest that a simple classification for prognosis according to diaphragm would not be wise, at least for DLBCL, in the era of rituximab. The present study was conducted to analyze the clinical importance of MTV between only nodal stages II and III DLBCL patients. Therefore, a further well-designed study including all nodal stages and extranodal sites is needed.

In conclusion, quantitative assessment of metabolic tumor volume using PET may potentially be more useful in the prediction of clinical outcome than the Ann Arbor staging system in stages II and III of exclusively nodal involved DLBCL patients treated with R-CHOP.
Acknowledgments This study was supported by a grant from the national R\&D Program for Cancer Control, Ministry for Health, Welfare and Family affairs, Republic of Korea (0920050) and supported by a grant of the Korean Health Technology R\&D Project, Ministry of Health and Welfare, Republic of Korea (A070001).

Disclosure statement None declared.

Open Access This article is distributed under the terms of the Creative Commons Attribution Noncommercial License which permits any noncommercial use, distribution, and reproduction in any medium, provided the original author(s) and source are credited.

\section{References}

1. Coiffier B, Lepage E, Briere J, Herbrecht R, Tilly H, Bouabdallah R, Morel P, Van Den Neste E, Salles G, Gaulard P, Reyes F, Lederlin P, Gisselbrecht C (2002) CHOP chemotherapy plus rituximab compared with $\mathrm{CHOP}$ alone in elderly patients with diffuse large-B-cell lymphoma. N Engl J Med 346:235-242

2. McKelvey EM, Gottlieb JA, Wilson HE, Haut A, Talley RW, Stephens R, Lane M, Gamble JF, Jones SE, Grozea PN, Gutterman J, Coltman C, Moon TE (1976) Hydroxyldaunomycin (adriamycin) combination chemotherapy in malignant lymphoma. Cancer 38:1484-1493

3. Fisher RI, Gaynor ER, Dahlberg S, Oken MM, Grogan TM, Mize EM, Glick JH, Coltman CA Jr, Miller TP (1993) Comparison of a standard regimen (CHOP) with three intensive chemotherapy regimens for advanced non-Hodgkin's lymphoma. N Engl J Med 328:1002-1006

4. Pfreundschuh M, Trümper L, Kloess M, Schmits R, Feller AC, Rudolph C, Reiser M, Hossfeld DK, Metzner B, Hasenclever D, Schmitz N, Glass B, Rübe C, Loeffler M (2004) Two-weekly or 3weekly CHOP chemotherapy with or without etoposide for the treatment of young patients with good-prognosis (normal LDH) aggressive lymphomas: results of the NHL-B1 trial of the DSHNHL. Blood 104:626-633

5. Feugier P, Van Hoof A, Sebban C, Solal-Celigny P, Bouabdallah R, Fermé C, Christian B, Lepage E, Tilly H, Morschhauser F, Gaulard P, Salles G, Bosly A, Gisselbrecht C, Reyes F, Coiffier B (2005) Long-term results of the R-CHOP study in the treatment of elderly patients with diffuse large B-cell lymphoma: a study by the Groupe d'Etude des Lymphomes de l'Adulte. J Clin Oncol 23:4117-4126

6. Habermann TM, Weller EA, Morrison VA, Gascoyne RD, Cassileth PA, Cohn JB, Dakhil SR, Woda B, Fisher RI, Peterson BA, Horning SJ (2006) Rituximab-CHOP versus CHOP alone or with maintenance rituximab in older patients with diffuse large B-cell lymphoma. J Clin Oncol 24:3121-3127

7. Pfreundschuh M, Trümper L, Osterborg A, Pettengell R, Trneny M, Imrie K, Ma D, Gill D, Walewski J, Zinzani PL, Stahel R, Kvaloy S, Shpilberg O, Jaeger U, Hansen M, Lehtinen T, LópezGuillermo A, Corrado C, Scheliga A, Milpied N, Mendila M, Rashford M, Kuhnt E, Loeffler M (2006) CHOP-like chemotherapy plus rituximab versus CHOP-like chemotherapy alone in young patients with good-prognosis diffuse large-B-cell lymphoma: a randomised controlled trial by the MabThera International Trial (MInT) Group. Lancet Oncol 7:379-391

8. Pfreundschuh M, Schubert J, Ziepert M, Schmits R, Mohren M, Lengfelder E, Reiser M, Nickenig C, Clemens M, Peter N, Bokemeyer C, Eimermacher H, Ho A, Hoffmann M, Mertelsmann R, Trümper L, Balleisen L, Liersch R, Metzner B, Hartmann F, Glass B, Poeschel V, Schmitz N, Ruebe C, Feller AC, Loeffler M 
(2008) Six versus eight cycles of bi-weekly CHOP-14 with or without rituximab in elderly patients with aggressive CD20+ B-cell lymphomas: a randomised controlled trial (RICOVER-60). Lancet Oncol 9:105-116

9. Lossos IS (2005) Molecular pathogenesis of diffuse large B-cell lymphoma. J Clin Oncol 23:6351-6357

10. Lossos IS, Morgensztern D (2006) Prognostic biomarkers in diffuse large B-cell lymphoma. J Clin Oncol 24:995-1007

11. Project TIN-HsLPF (1993) A predictive model for aggressive nonHodgkin's lymphoma. The International Non-Hodgkin's Lymphoma Prognostic Factors Project. N Engl J Med 329:987-994

12. Spaepen K, Stroobants S, Dupont P, Vandenberghe P, Thomas J, de Groot T, Balzarini J, De Wolf-Peeters C, Mortelmans L, Verhoef G (2002) Early restaging positron emission tomography with (18) F-fluorodeoxyglucose predicts outcome in patients with aggressive non-Hodgkin's lymphoma. Ann Oncol 13:1356-1363

13. Haioun C, Itti E, Rahmouni A, Brice P, Rain JD, Belhadj K, Gaulard P, Garderet L, Lepage E, Reyes F, Meignan M (2005) [18F] Fluoro-2-deoxy-D-glucose positron emission tomography (FDG-PET) in aggressive lymphoma: an early prognostic tool for predicting patient outcome. Blood 106:1376-1381

14. Cheson BD, Pfistner B, Juweid ME, Gascoyne RD, Specht L, Horning SJ, Coiffier B, Fisher RI, Hagenbeek A, Zucca E, Rosen ST, Stroobants S, Lister TA, Hoppe RT, Dreyling M, Tobinai K, Vose JM, Connors JM, Federico M, Diehl V (2007) Revised response criteria for malignant lymphoma. J Clin Oncol 25:579586

15. Carbone PP, Kaplan HS, Musshoff K, Smithers DW, Tubiana M (1971) Report of the Committee on Hodgkin's Disease Staging Classification. Cancer Res 31:1860-1861

16. Lister TA, Crowther D, Sutcliffe SB, Glatstein E, Canellos GP, Young RC, Rosenberg SA, Coltman CA, Tubiana M (1989) Report of a committee convened to discuss the evaluation and staging of patients with Hodgkin's disease: Cotswolds meeting. J Clin Oncol 7:1630-1636

17. Freudenberg LS, Antoch G, Schütt P, Beyer T, Jentzen W, Müller SP, Görges R, Nowrousian MR, Bockisch A, Debatin JF (2004) FDG-PET/CT in re-staging of patients with lymphoma. Eur J Nucl Med Mol Imaging 31:325-329

18. Jagannath S, Velasquez WS, Tucker SL, Fuller LM, McLaughlin PW, Manning JT, North LB, Cabanillas FC (1986) Tumor burden assessment and its implication for a prognostic model in advanced diffuse large-cell lymphoma. J Clin Oncol 4:859-865

19. Ziepert M, Hasenclever D, Kuhnt E, Glass B, Schmitz N, Pfreundschuh M, Loeffler M (2010) Standard international prognostic index remains a valid predictor of outcome for patients with aggressive CD20+ B-cell lymphoma in the rituximab era. J Clin Oncol 28:2373-2380

20. Wu X, Dastidar P, Pertovaara H, Korkola P, Järvenpää R, Rossi M, Kööbi T, Eskola H, Kellokumpu-Lehtinen PL (2010) Early treatment response evaluation in patients with diffuse large B-cell lymphomaa pilot study comparing volumetric MRI and PET/CT. Mol Imaging Biol 13:785-792

21. Wu X, Kellokumpu-Lehtinen PL, Pertovaara H, Korkola P, Soimakallio S, Eskola H, Dastidar P (2011) Diffusion-weighted MRI in early chemotherapy response evaluation of patients with diffuse large B-cell lymphoma-a pilot study: comparison with 2deoxy-2-fluoro-D-glucose-positron emission tomography/computed tomography. NMR Biomed (in press)

22. Spratt DE, Diaz R, McElmurray J, Csiki I, Duggan D, Lu B, Delbeke D (2010) Impact of FDG PET/CT on delineation of the gross tumor volume for radiation planning in non-small-cell lung cancer. Clin Nucl Med 35:237-243

23. La TH, Filion EJ, Turnbull BB, Chu JN, Lee P, Nguyen K, Maxim P, Quon A, Graves EE, Loo BW Jr, Le QT (2009) Metabolic tumor volume predicts for recurrence and death in head-and-neck cancer. Int J Radiat Oncol Biol Phys 74:1335-1341 